\title{
ANALISIS SWOT SEBAGAI PENENTU STRATEGI PEMASARAN PADA RUMAH SAKIT GIGI DAN MULUT BAITURRAHMAH PADANG
}

\author{
Hanim Khalida Zia ${ }^{1}$, Rima Semiarty², Ratni Prima Lita ${ }^{3}$
}

\begin{abstract}
Abstrak
Jumlah kunjungan pasien Instalasi Rawat Jalan Rumah Sakit Gigi dan Mulut Baiturrahmah Padang pada tahun 2016 yaitu 27.933 kunjungan. Pada tahun 2017 mengalami penurunan $(41,7 \%)$ yaitu 16.288 kunjungan. Sedangkan, pada tahun 2018 mengalami sedikit peningkatan (3,7\%) yaitu 16.884 kunjungan. Setiap rumah sakit harus dapat membuat suatu strategi pemasaran yang tepat untuk dapat bersaing dimasa sekarang dan akan datang. Salah satu upaya strategi pemasaran adalah analisis SWOT. Analisis SWOT mengidentifikasi strengths (kekuatan) dan weaknesses (kelemahan) pada aspek internal serta opportunities (peluang) dan threats (ancaman) pada aspek eksternal perusahaan. Penelitian ini bertujuan untuk mengetahui strategi pemasaran yang dapat dilakukan oleh Rumah Sakit Gigi dan Mulut Baiturrahmah Padang berdasarkan analisis SWOT. Jenis penelitian adalah kualitatif. Informan terdiri dari Pemilik, Direktur, Wakil Direktur, Karyawan, Mahasiswa, Pasien dan Masyarakat yang tinggal di sekitar Rumah Sakit Gigi dan Mulut Baiturrahmah Padang. Hasil penelitian menunjukkan bahwa strategi SO (Strengths Opportunities): meningkatkan kualitas kesehatan pelayanan gigi dan mulut, menjalin kerja sama dengan instansi di bidang kesehatan, menggunakan alat dan bahan terbaru dan menjadi pusat rujukan pelayanan kesehatan gigi dan mulut. Strategi WO (Weaknesses Opportunities): menyelesaikan proses akreditasi, pengaturan jadwal dan tarif dokter, melakukan promosi melalui berbagai media dan menambah jumlah SDM untuk kegiatan pemasaran. Strategi ST (Strengths Threats): meningkatkan pelayanan unggulan di bidang periodonsia dengan pelatihan kepada karyawan dan membuat pendaftaran online. Sedangkan, strategi WT (Weaknesses Threats): membentuk bagian pemasaran untuk meningkatkan kegiatan promosi.
\end{abstract}

Kata Kunci: analisis SWOT, strategi pemasaran, Rumah Sakit Gigi dan Mulut Baiturrahmah Padang

\begin{abstract}
The number of outpatient visits at Baiturrahmah Padang Dental Hospital in 2016 there are 27,933 visits. In 2017 there are a decrease (41,7\%) there are 16,288 visits. Whereas, in 2018 there are a little increase $(3,7 \%)$ there are 16,884 visits. Every hospital has to be able to make an appropriate marketing strategy to be able to compete in the present and future. One of the marketing strategy effort is SWOT analysis. SWOT analysis identify the strengths and weaknesses in the internal aspects, opportunities and threats in the external aspects of the company. This study aimed to determine the marketing strategy that could be done by Baiturrahmah Padang Dental Hospital based on SWOT analysis. This research was qualitative study. The informant consisted of the Owner, Director, Deputy Director, Employees, Students, Patients and societies who stay around Baiturrahmah Padang Oral and Dental Hospital. The results showed that SO strategy (Strengths Opportunities): improve the quality of oral and dental health services, establish cooperation with relevant agencies, use the latest tools and materials and become a reference center for oral and dental health services. WO strategy (Weaknesses Opportunities): complete the accreditation process, set the doctor's fee and schedule, do promotion through various media and add the number of human resources for marketing activities. ST strategy (Strengths Threats): improves superior medical in periodonsia by training employees and make online registration. WT strategy (Weaknesses Threats): forming a marketing department to improve promotion activities.
\end{abstract}

Keywords: SWOT analysis, marketing strategy, Baiturrahmah Padang Dental Hospital

Affiliasi penulis: 1. Rumah Sakit Gigi dan Mulut (Fakultas Kedokteran Gigi Universitas Baiturrahmah), 2. Bagian IImu Kesehatan Masyarakat FK Unand (Fakultas Kedokteran Universitas Andalas), 3. Bagian Master Manajemen FE Unand (Fakultas Ekonomi Universitas Andalas)

Korespondensi: Rima Semiarty e-mail: rimamenkher@yahoo.com Telp/HP: 08126608040

\section{PENDAHULUAN}

Jumlah kunjungan pasien Instalasi Rawat Jalan RSGM Baiturrahmah Padang pada tahun 2016 yaitu sebanyak 27.933 kunjungan. Sedangkan, pada tahun 2017 mengalami penurunan yaitu menjadi sebanyak 16.288 kunjungan dan sampai bulan Oktober tahun 2018 sebanyak 13.687 kunjungan.
Setiap rumah sakit harus dapat membuat suatu strategi pemasaran yang tepat dan dapat membuat suatu perencanaan untuk dapat bersaing dimasa sekarang dan akan datang. Strategi tersebut diperlukan untuk dapat meningkatkan daya saing di antara perusahaan yang sejenis. Salah satu upaya untuk mengetahui strategi pemasaran yang tepat bagi rumah sakit adalah dengan analisis SWOT. ${ }^{1}$ Analisis SWOT dapat digunakan untuk menyebarkan strategi yang dikembangkan dalam rangka untuk menjadi sukses di lingkungan global di masa depan. ${ }^{2}$

Analisis SWOT adalah metode dalam riset pemasaran yang digunakan dalam menganalisis faktor lingkungan yang kompetitif. Analisis SWOT mengidentifikasi berbagai faktor secara sistematis 
untuk merumuskan strategi rumah sakit. ${ }^{3}$ Secara umum, penentuan strategi yang tepat bagi rumah sakit dimulai dengan memahami strengths (kekuatan) dan weaknesses (kelemahan) pada aspek internal serta mengenali opportunities (peluang) dan threats (ancaman) yang terkandung dalam lingkungan eksternal perusahaan. ${ }^{4}$ Dengan demikian, perusahaan mampu bersaing dan mencapai tujuan secara efektif dan efisien. ${ }^{5}$

Berdasarkan latar belakang dan uraian di atas, penulis tertarik melakukan penelitian mengenai analisis SWOT untuk mengetahui strategi pemasaran yang dapat dilakukan oleh RSGM Baiturrahmah Padang.

\section{METODE}

Jenis penelitian yang digunakan dalam penelitian ini adalah kualitatif. Penelitian ini dilakukan di RSGM Baiturrahmah Padang pada bulan JuliNovember 2018. Sumber data terdiri dari sumber data primer dan sekunder. Sumber data primer didapatkan dari hasil wawancara mendalam dengan informan. Data sekunder didapatkan dari sumber tertulis berupa studi dokumen yang ada di RSGM Baiturrahmah Padang. Teknik pengumpulan data yaitu observasi, wawancara mendalam, studi dokumentasi dan focus group discussion. ${ }^{6}$

Total jumlah informan dalam penelitian ini adalah sebanyak 19 orang yang terdiri dari: pemilik, direktur, wakil direktur sebanyak 2 orang, karyawan sebanyak 1 orang, mahasiswa sebanyak 1 orang, pasien sebanyak 3 orang dan masyarakat yang tinggal di sekitar RSGM Baiturrahmah Padang sebanyak 10 orang.

Analisa data dilakukan dengan tahapan berikut:

1. Tahap Input (Analisis Lingkungan Internal dan Eksternal)

a. Analisis Komparatif

Analisis ini diperlukan untuk memperoleh bobot yang akan dimasukkan ke dalam matriks IFE (Internal Factor Evaluation) dan matriks EFE (External Factor
Evaluation). Metode ini dilakukan dengan cara membandingkan 2 faktor yang berbeda dalam satu kategori yang sama berdasarkan tingkat kepentingan bagi pengembangan RSGM Baiturrahmah Padang. Dalam menentukan bobot setiap variabel digunakan skala 1, 2 dan 3 dalam pengisian kolom dengan penjelasan sebagai berikut:

1 = Jika faktor horizontal kurang penting dibandingkan faktor vertikal.

2 = Jika faktor horizontal sama penting dibandingkan faktor vertikal.

3 = Jika faktor horizontal lebih penting dibandingkan faktor vertikal.

b. Analisis IFE (Internal Factor Evaluation) dan EFE (External Factor Evaluation) Analisis IFE/EFE dilakukan dengan cara membuat matriks yang terdiri dari kolom pembobotan, rating kekuatan, kelemahan, peluang dan ancaman seperti berikut:

1) Kolom 2, faktor kekuatan, kelemahan, peluang dan ancaman.

2) Kolom 3, pembobotan antara 1 (sangat penting) sampai 0 (tidak penting).

3) Kolom 4, memberikan rating dengan skala 4 (outstanding) sampai 1 (poor).

4) Kolom 5, pengalian antara bobot (kolom 2) dengan rating (kolom 3 ).

2. Tahapan Proses

a. Analisis SWOT (Strengths, Weaknesses, Opportunities, Threats)

Masing-masing kekuatan (strengths), kelemahan (weaknesses), peluang (opportunities) dan ancaman (threats) dengan nilai tertinggi dalam analisis komparatif, kemudian dimasukkan ke dalam matriks SWOT.

b. Matriks IE

Gabungan kedua matriks IFE dan matriks EFE menghasilkan matriks internal-eksternal yang berisikan 9 macam sel yang memperlihatkan kombinasi total skor dari matriks IFE dan matriks EFE.

\section{HASIL}

Hasil reduksi wawancara mendalam tentang kekuatan RSGM Baiturrahmah Padang dapat dilihat pada tabel 1 berikut ini.

Tabel 1. Hasil Reduksi Wawancara Mendalam tentang Kekuatan RSGM Baiturrahmah Padang

\begin{tabular}{|c|c|c|}
\hline Topik & Analisa Jawaban & Kesimpulan \\
\hline Kekuatan & $\begin{array}{l}\text { a. RSGM Baiturrahmah Padang sudah memili } \\
\text { semua spesialis di bidang kedokteran gigi } \\
\text { b. Memiliki sarana dan prasarana yang baru } \\
\text { dan lengkap } \\
\text { c. Menyediakan pelayanan yang langsung } \\
\text { diberikan oleh dokter gigi dan dokter gigi } \\
\text { spesialis } \\
\text { d. Memiliki izin operasional dengan kelas } \\
\text { tipe B } \\
\text { e. Banyak rujukan dari daerah-daerah untuk } \\
\text { mendapatkan pelayanan dokter gigi } \\
\text { spesialis }\end{array}$ & $\begin{array}{l}\text { a. Memiliki semua spesialis di bidang } \\
\text { kedokteran gigi } \\
\text { b. Memiliki sarana dan prasarana yang } \\
\text { memadai } \\
\text { c. Menyediakan pelayanan oleh drg dan drg } \\
\text { spesialis } \\
\text { d. Memiliki izin operasional RSGM } \\
\text { e. Menjadi tempat rujukan }\end{array}$ \\
\hline
\end{tabular}

Hasil reduksi wawancara mendalam tentang kelemahan RSGM Baiturrahmah Padang dapat dilihat pada tabel 2 berikut ini. 
Tabel 2. Hasil Reduksi Wawancara Mendalam tentang Kelemahan RSGM Baiturrahmah Padang

\begin{tabular}{|c|c|c|}
\hline Topik & Analisa Jawaban & Kesimpulan \\
\hline Kelemahan & 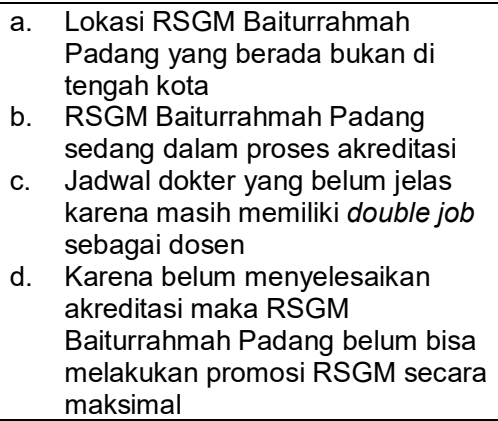 & $\begin{array}{l}\text { a. Lokasi tidak di tengah kota } \\
\text { b. Belum terakreditasi } \\
\text { c. Jadwal dan tarif dokter belum } \\
\text { d. Kesuai } \\
\text { Kurangnya promosi }\end{array}$ \\
\hline
\end{tabular}
berikut ini.

Hasil reduksi wawancara mendalam tentang peluang RSGM Baiturrahmah Padang dapat dilihat pada tabel 3

Tabel 3. Hasil Reduksi Wawancara Mendalam tentang Peluang RSGM Baiturrahmah Padang

\begin{tabular}{|c|c|c|}
\hline Topik & Analisa Jawaban & Kesimpulan \\
\hline Peluang & $\begin{array}{l}\text { a. Pasien bisa merekomendasikan pasien lain } \\
\text { untuk berobat di RSGM Baiturrahmah } \\
\text { Padang (Word of Mouth) } \\
\text { b. Menjalin kerja sama dengan berbagai } \\
\text { instansi untuk meningkatkan kunjungan } \\
\text { pasien } \\
\text { c. Meningkatkan kualitas pelayanan dengan } \\
\text { mengikuti perkembangan teknologi yang } \\
\text { demakin maju } \\
\text { d. Dengan adanya kepercayaan dari instansi } \\
\text { yang telah bekerja sama dengan RSGM } \\
\text { Baiturrahmah Padang }\end{array}$ & $\begin{array}{ll}\text { a. Promosi dari pasien (Word of } \\
\text { Mouth) } \\
\text { b. Kerja sama dengan instansi terkait } \\
\text { c. Perkembangan teknologi yang } \\
\text { semakin maju } \\
\text { d. Kepercayaan dari instansi yang } \\
\text { telah bekerja sama }\end{array}$ \\
\hline
\end{tabular}

Hasil reduksi wawancara mendalam tentang ancaman RSGM Baiturrahmah Padang dapat dilihat pada tabel 4 berikut ini.

Tabel 4. Hasil Reduksi Wawancara Mendalam tentang Ancaman RSGM Baiturrahmah Padang

\begin{tabular}{|c|c|c|}
\hline Topik & Analisa Jawaban & Kesimpulan \\
\hline Ancaman & $\begin{array}{l}\text { a. Adanya pesaing yang semakin } \\
\text { berbenah untuk memajukan RSGM nya } \\
\text { b. Banyaknya ahli/tukang gigi yang } \\
\text { berpraktek } \\
\text { c. Media sosial dapat dijadikan sebagai } \\
\text { wadah promosi oleh pesaing, sehingga } \\
\text { promosinya bisa lebih gencar }\end{array}$ & $\begin{array}{l}\text { a. RSGM pesaing di Padang } \\
\text { b. Ahli/tukang gigi yang } \\
\text { semakin berani } \\
\text { berpraktek } \\
\text { c. Media sosial sehingga } \\
\text { promosi pesaing lebih } \\
\text { gencar }\end{array}$ \\
\hline
\end{tabular}

\section{Matriks IFE RSGM Baiturrahmah Padang}

Matriks IFE dapat dilihat pada tabel 5 berikut ini .

Tabel 5. Matriks IFE RSGM Baiturrahmah Padang

\begin{tabular}{|c|c|c|c|c|}
\hline No. & Faktor Kunci & Bobot & Rating & $\begin{array}{c}\text { Skor } \\
\text { Pembobotan }\end{array}$ \\
\hline & Kekuatan (Strengths) & & & \\
\hline 1. & Memiliki semua spesialis di bidang kedokteran gigi & 0,0975 & 4 & 0,39 \\
\hline 2. & Memilii sarana dan prasarana yang memadai & 0,0975 & 4 & 0,39 \\
\hline 3. & Menyediakan pelayanan oleh drg dan drg spesialis & 0,0975 & 2 & 0,195 \\
\hline 4. & Memiliki izin operasional RSGM & 0,1465 & 4 & 0,586 \\
\hline \multirow[t]{2}{*}{5.} & Menjadi tempat rujukan & 0,061 & 3 & 0,183 \\
\hline & $\begin{array}{c}\text { Sub Total } \\
\text { Kelemahan (Weaknesses) }\end{array}$ & 0,5 & & 1,744 \\
\hline 1. & Lokasi tidak di tengah kota & 0,0625 & 3 & 0,1875 \\
\hline 2. & Belum terakreditasi & 0,16665 & 1 & 0,16665 \\
\hline 3. & Jadwal dan tarif dokter belum sesuai & 0,16665 & 1 & 0,16665 \\
\hline \multirow[t]{3}{*}{4.} & Kurangnya promosi & 0,1042 & 2 & 0,2084 \\
\hline & Sub Total & 0,5 & & 0,7292 \\
\hline & Total & 1 & & 2,4732 \\
\hline
\end{tabular}

Keterangan:

Kolom 3 = Pembobotan antara 1 (sangat penting) sampai 0 (tidak penting).

Kolom 4 = Rating dengan skala 4 (outstanding) sampai 1 (poor).

Kolom 5 = Pengalian antara bobot (kolom 2) dengan rating (kolom 3). 


\section{Matriks EFE RSGM Baiturrahmah Padang}

Matriks EFE dapat dilihat pada tabel 6 berikut ini.

Tabel 6. Matriks EFE RSGM Baiturrahmah Padang

\begin{tabular}{|c|c|c|c|c|}
\hline No. & Faktor Kunci & Bobot & Rating & $\begin{array}{c}\text { Skor } \\
\text { Pembobotan }\end{array}$ \\
\hline & Peluang (Opportunities) & & & \\
\hline 1. & Promosi dari pasien (Word of Mouth) & 0,125 & 4 & 0,5 \\
\hline 3. & Perkembangan teknologi yang semakin maju & 0,146 & 4 & 0,584 \\
\hline \multirow[t]{2}{*}{4.} & Kepercayaan dari instansi yang telah bekerja sama & 0,146 & 4 & 0,584 \\
\hline & $\begin{array}{c}\text { Sub Total } \\
\text { Ancaman (Threats) }\end{array}$ & 0,5 & & 2 \\
\hline 2. & Alhi/tukang gigi yang semakin berani berpraktek & 0,13635 & 1 & 0,13635 \\
\hline \multirow[t]{3}{*}{3.} & Media sosial sehingga promosi pesaing lebih gencar & 0,2273 & 2 & 0,4546 \\
\hline & Sub Total & 0,5 & & 0,7273 \\
\hline & Total & 1 & & 2,7273 \\
\hline
\end{tabular}

Keterangan:

Kolom 3 = Pembobotan antara 1 (sangat penting) sampai 0 (tidak penting)

Kolom 4 = Rating dengan skala 4 (outstanding) sampai 1 (poor).

Kolom 5 = Pengalian antara bobot (kolom 2) dengan rating (kolom 3).

\section{Matriks SWOT RSGM Baiturrahmah Padang}

Matriks SWOT dapat dilihat pada tabel 7 berikut ini.

Tabel 7. Matriks SWOT RSGM Baiturrahmah Padang

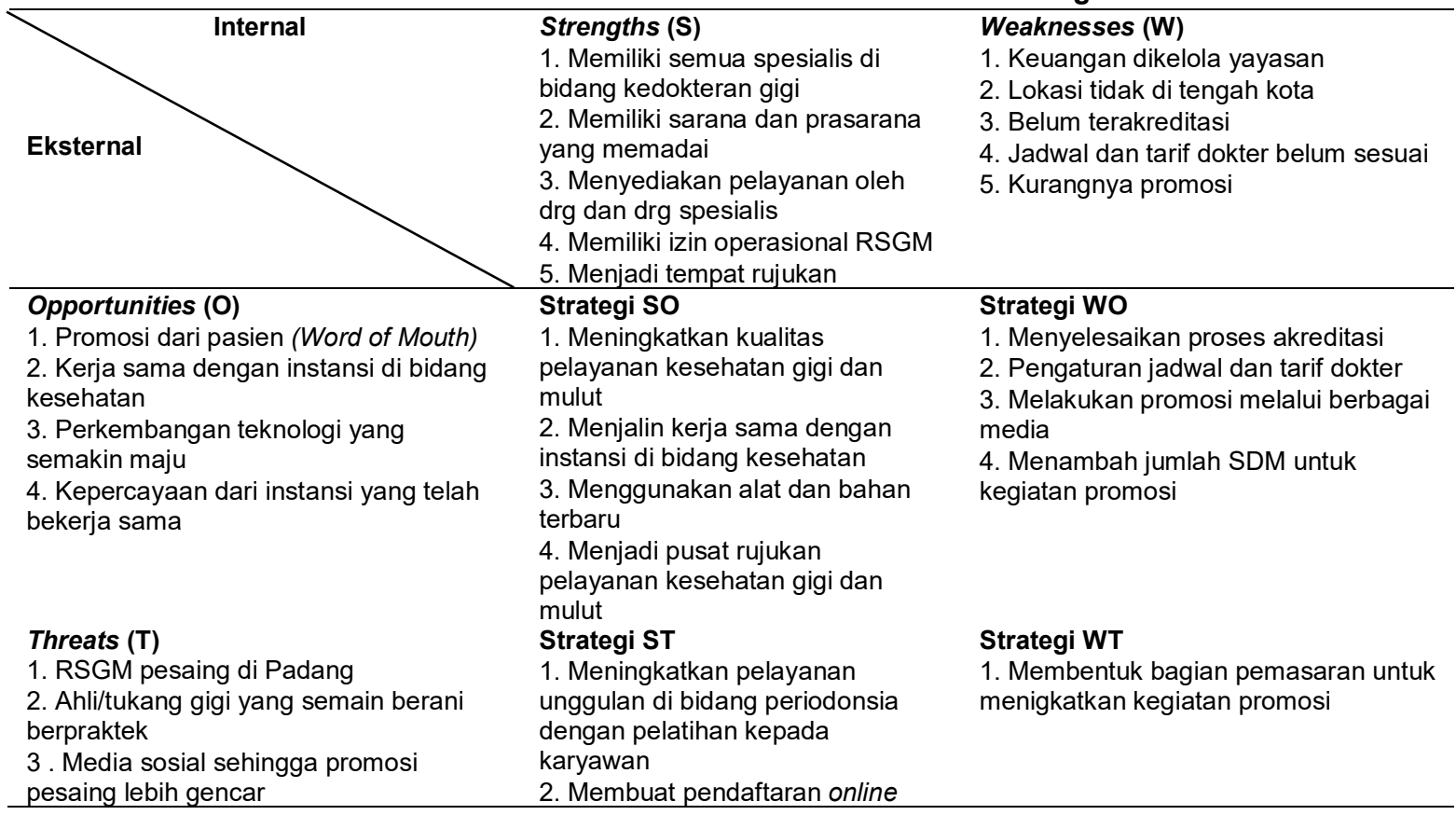

\section{Matriks IE RSGM Baiturrahmah Padang}

Matriks IE dapat dilihat pada gambar 1 berikut ini.

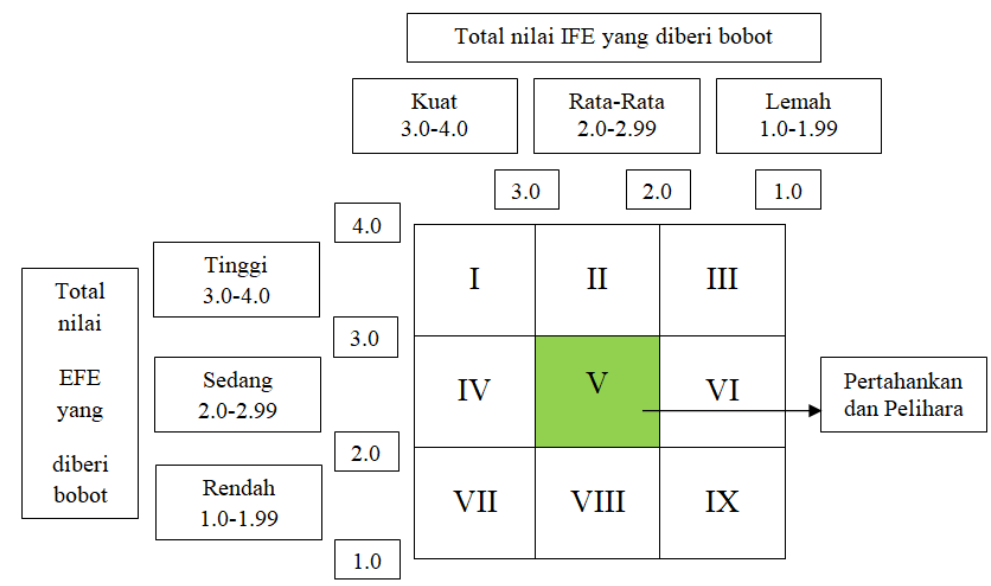

Gambar 1 . Matriks IE RSGM Baiturrahmah Padang 


\section{PEMBAHASAN}

Segala hal yang dibutuhkan pada kondisi yang sifatnya internal RSGM Baiturrahmah Padang agar pelayanan kesehatan gigi dan mulut berjalan maksimal merupakan kekuatan bagi RSGM Baiturrahmah Padang. Adapun kekuatan utama RSGM Baiturrahmah Padang adalah memiliki izin operasional RSGM. Selanjutnya diikuti oleh memiliki semua spesialis di bidang kedokteran gigi, memiliki sarana dan prasarana yang memadai, menyediakan pelayanan oleh drg dan drg spesialis dan terakhir yaitu menjadi tempat rujukan.

Hal ini sesuai dengan Peraturan Menteri Kesehatan Republik Indonesia Nomor 1173/Menkes/Per/X/2004 Tentang Rumah Sakit Gigi dan Mulut Pasal 21 Ayat (1) Penyelenggaraan RSGM harus mendapat izin dari Dinas Kesehatan Propinsi. Ayat (2) Izin sebagaimana dimaksud dalam ayat (1) meliputi izin mendirikan dan penyelenggaraan. Pasal 23 Ayat (1) Izin penyelenggaraan sebagaimana dimaksud dalam Pasal 21 berlaku selama 5 (lima) tahun dan dapat diperpanjang lagi. ${ }^{7}$

Kekurangan pada kondisi internal RSGM Baiturrahmah Padang, akibatnya pelayanan kesehatan gigi dan mulut belum maksimal terlaksana merupakan kelemahan bagi RSGM Baiturrahmah Padang. Adapun kelemahan utama RSGM Baiturrahmah Padang adalah belum terakreditasi dan jadwal dan tarif dokter belum sesuai. Selanjutnya diikuti oleh kurangnya promosi dan lokasi tidak di tengah kota.

Berdasarkan Peraturan Menteri Kesehatan Republik Indonesia Nomor 1173/Menkes/Per/X/2004 Tentang Rumah Sakit Gigi dan Mulut Pasal 1 Dalam peraturan ini yang dimaksud dengan: Akreditasi adalah pengakuan yang diberikan oleh pemerintah atau badan akreditasi yang berwenang kepada rumah sakit gigi dan mulut yang telah memenuhi standar pelayanan yang ditentukan. Pasal 28 Ayat (1) Akreditasi RSGM dilakukan setiap 3 (tiga) tahun sekali. Ayat (2) Akreditasi RSGM dilaksanakan pada RSGM yang mempunyai izin penyelenggaraan yang masih berlaku. Ayat (3) Akreditasi sebagai RSGM Pendidikan dilakukan melalui Komisi Akreditasi Rumah Sakit yang bersifat independen. Ayat (4) Pelaksanaan akreditasi RSGM ditetapkan lebih lanjut oleh Menteri. $^{7}$

Faktor-faktor lingkungan luar yang positif, yang dapat dan mampu mengarahkan pelayanan kesehatan gigi dan mulut RSGM Baiturrahmah Padang menuju tujuannya merupakan peluang bagi RSGM Baiturrahmah Padang. Adapun peluang utama RSGM Baiturrahmah Padang adalah perkembangan teknologi yang semakin maju dan kepercayaan dari instansi yang telah bekerja sama. Selanjutnya diikuti oleh promosi dari pasien (Word of Mouth) dan kerja sama dengan instansi di bidang kesehatan.

Faktor-faktor lingkungan luar yang mampu menghambat pergerakan RSGM Baiturrahmah
Padang merupakan ancaman bagi RSGM Baiturrahmah Padang. Adapun ancaman utama RSGM Baiturrahmah Padang adalah media sosial sehingga promosi pesaing lebih gencar. Selanjutnya diikuti oleh RSGM pesaing di Padang dan ahli/tukang gigi yang semakin berani berpraktek.

Berdasarkan Peraturan Menteri Kesehatan Republik Indonesia Nomor 1173/Menkes/Per/X/2004 Tentang Rumah Sakit Gigi dan Mulut, Dengan Rahmat Tuhan Yang Maha Esa Menteri Kesehatan Republik Indonesia, Memutuskan: Menetapkan: Peraturan Menteri Kesehatan Republik Indonesia tentang Rumah Sakit Gigi dan Mulut. ${ }^{7}$

Matriks IFE menunjukkan bahwa total dari bobot kekuatannya adalah sebesar 1,744 , sedangkan total dari bobot kelemahannya adalah sebesar 0,7292. Dengan melihat perbandingan antara kekuatan dan kelemahan, maka terdapat perbedaaan nilai yang sangat signifikan sehingga dapat disimpulkan bahwa RSGM Baiturrahmah Padang dapat dengan baik memberdayakan kekuatannya dan berusaha menutupi berbagai kelemahan dari perusahaannya. Jadi total skor IFE RSGM Baiturrahmah Padang adalah sebesar 2,4732. Hal ini sangat jelas menunjukan bahwa RSGM Baiturrahmah Padang telah berhasil mengelola kekuatan internalnya dan mengatasi kelemahannya dengan baik. Dengan begitu, berarti RSGM Baiturrahmah Padang memiliki posisi internal yang kuat (Strong Internal Position).

Matriks EFE menunjukkan bahwa total bobot peluang RSGM Baiturrahmah Padang adalah sebesar 2 , sedangkan total dari bobot dari ancaman adalah sebesar 0,7273. Dengan melihat perbandingan antara peluang dan ancaman, maka terdapat nilai yang sangat signifikan sehingga dapat disimpulkan bahwa peluang yang dimiliki RSGM Baiturrahmah Padang bisa dimanfaatkan untuk menutup Ancaman yang ada. Jadi total skor EFE RSGM Baiturrahmah Padang adalah sebesar 2,7273.

Dari matrik SWOT diatas dapat dilihat bahwa faktor kekuatan lebih besar dibandingkan dengan faktor kelemahan yang dimiliki oleh RSGM Baiturrahmah Padang dan faktor peluang juga lebih besar bila dibandingkan dengan faktor ancaman. Oleh karena itu kondisi RSGM Baiturrahmah Padang seharusnya sudah cukup mampu untuk bersaing dengan lembaga-lembaga lain yang bergerak di bidang yang sama.

RSGM Baiturrahmah Padang berada pada sel $\checkmark$ yaitu pertahankan dan pelihara. Strategi yang paling sesuai dilakukan yaitu penetrasi pasar dan pengembangan produk khususnya pelayanan unggulan di bidang periodonsia berdasarkan 10 penyakit terbanyak dan sudah adanya 2 orang Sp.Perio di RSGM Baiturrahmah Padang. RSGM Baiturrahmah Padang dapat melakukan suatu kegiatan meningkatkan jenis pelayanan kepada pasien, meningkatkan fasilitas dan teknologi melalui pengembangan internal maupun eksternal melalui akuisisi atau joint venture dengan instansi lain baik 
dalam kesehatan maupun dengan instansi yang mendukung kelancaran pelayanan yang diberikan oleh RSGM Baiturrahmah Padang.

\section{SIMPULAN}

Berdasarkan penelitian yang telah dilakukan oleh peneliti, hasil analisis SWOT menyebutkan bahwa RSGM Baiturrahmah Padang sudah mampu bersaing dipasar persaingan yang kompetitif. Berdasarkan analisis SWOT, strategi pemasaran yang dapat dilakukan yaitu strategi SO (Strenghts Opportunities) yang meliputi peningkatan kualitas pelayanan kesehatan gigi dan mulut, penjalinan kerja sama dengan instansi di bidang kesehatan, penggunaan alat dan bahan terbaru dan pusat rujukan pelayanan kesehatan gigi dan mulut.

Strategi WO (Weaknesses Opportunities) yakni penyelesaian proses akreditasi, pengaturan jadwal dan tarif dokter, promosi melalui berbagai media dan penambahan jumlah SDM untuk kegiatan promosi. Strategi ST (Strenghts Threats) terdiri dari peningkatan pelayanan unggulan di bidang periodonsia dengan pelatihan kepada karyawan dan pembuatan pendaftaran online. Sedangkan, strategi WT (Weaknesses Threats) yaitu pembentukan bagian pemasaran untuk meningkatakan kegiatan promosi.

\section{DAFTAR PUSTAKA}

1. Kotler P. Manajemen Pemasaran Jilid 1. Penerjemah: Benyamin Molan. Jakarta: Indeks; 2009. Ed ke 11.

2. Aslan I, Cinar O, Ozen U. Developing Strategies for the Future of Healthcare in Turkey by Benchmarking and SWOT Analysis. ProcediaSocial and Behavioral Sciences. 2014;150:230240.

3. Rangkuti F. Analisis SWOT. Jakarta: Gramedia; 2013. Ed ke 17.

4. Scotti E, Pietrantonio F. The Hospital Internal Medicine Specialist Today: A Literature Review and Strength, Weaknesses, Opportunity, Threats (SWOT) Analysis to Develop A Working Proposal. Italian Journal of Medicine. 2013;7(4):278-286.

5. Kotler $\mathrm{P}$, Keller KL. Manajemen Pemasaran. Jakarta: Erlangga; 2009. Ed ke 13.

6. Satori D, Komariah A. Metodologi Penelitian Kualitatif. Bandung: Alfabeta; 2010.

7. Peraturan Menteri Kesehatan Republik Indonesia Nomor 1173 Tahun 2004 Tentang Rumah Sakit Gigi dan Mulut. Jakarta. 